\title{
Las palabras y las cosas en la ciudad latinoamericana. Obstáculos epistemológicos en políticas urbanas argentinas*
}

\author{
Words and things in the Latin American city. \\ Epistemological obstacles in Argentinean urban policies
}

Ana Núñez Jorge Roze

\begin{abstract}
Resumen
El artículo invita al debate sobre los procesos de producción de saberes, teorías y marcos conceptuales que operaron y operan en el conocimiento sobre la ciudad latinoamericana, junto a la formulación de políticas urbanas. Nos adentramos, fundamentalmente, en la constitución de las categorías dominantes que operan en la reflexión, y la construcción de pseudonecesidades como políticas urbanas. Abordamos la revisión de las bases epistemológicas de este pensamiento, haciendo observable sus limitaciones, y proponemos un retorno a un conjunto de reflexiones, presentes en las investigaciones que venimos desarrollando desde fines de la década de 1980, ancladas empíricamente en dos ciudades intermedias argentinas.
\end{abstract}

Palabras claves: procesos de conocimiento; obstáculos epistemológicos; estilos investigativos; fetichismos; políticas urbanas.

\begin{abstract}
We propose a discussion about the processes of production of knowledge, theories and conceptual frameworks that have operated and will operate in the construction of knowledge about Latin American cities, together with the formulation of urban policies. We focus on the constitution of the dominant categories that influence the reflection and construction of pseudo-needs as urban policies. We approach the revision of the epistemological foundations of this thought, carefully observing their limitations, and propose a return to a set of reflections present in the research that we have been developing since the late 1980s in medium-sized cities in Argentina.
\end{abstract}

Keywords: knowledge process; epistemological obstacles; investigative st yles; fetishism ; urban policies. 


\section{Introducción}

"El pensamiento surge desde el lugar donde se halla el cuerpo: acomodado, o en conflicto". Eduardo Rosenzvaig (2004, p. 175)

Este texto plantea una invitación a debatir sobre los procesos de producción de saberes, teorías y marcos conceptuales que operaron y operan en el conocimiento de las ciudades latinoamericanas, en general, junto a la formulación de políticas urbanas en dos ciudades intermedias argentinas, en particular. Nos adentramos en aspectos particulares de esas teorías. Uno de ellos, vinculado con el dominio de los estudios sobre las metrópolis, donde los problemas urbanos son tratados como problemas metropolitanos. Otro, sobre la constitución de las categorías dominantes que operan en la reflexión, construcción de pseudonecesidades como políticas urbanas, y la fetichización de los sujetos operantes. Es decir, su constitución en un sentido común que tiñe linealmente el pensamiento de los investigadores de la ciencia "normal" y sus derivados, y su emergencia como políticas públicas.

Para ello, abordamos en la primera parte la revisión de las bases epistemológicas de este pensamiento, haciendo observable sus limitaciones, y proponemos un retorno a un conjunto de reflexiones, presentes en las investigaciones que venimos desarrollando desde fines de la década de 1980. Estas reflexiones emergen a partir de invertir y abrir el problema investigativo y sus categorías, que han operado hegemónicamente en la literatura especializada.
A los efectos de ejemplificar la brecha entre teorías y realidad de la investigación que denominamos como "normal", en la segunda parte ponemos en movimiento dichas categorías a partir de su anclaje empírico en dos políticas urbanas, desenvueltas en dos ciudades intermedias argentinas. La selección de dichas políticas, las luchas por y con el agua y el saneamiento, en Mar del Plata, y la construcción de defensas, en torno a las inundaciones, en Resistencia, ${ }^{1}$ tiene su fundamento no sólo en la potencialidad de su matriz teórico-metodológica y empírica para sostener nuestros argumentos, y pensar las políticas urbanas, sino que han sido reconstruidas históricamente por los autores de este texto, pues atraviesan axialmente las condiciones de vida de nuestras sociedades. Por último, recuperar su historicidad, en términos de mediciones cruciales, torna observables otros procesos explicativos de lo que se denomina "política urbana", soslayados por la bibliografía latinoamericana, en general.

\section{Apertura del problema²}

Como planteáramos en un trabajo anterior (Núñez y Roze, 2011), dos estilos de búsquedas de explicación de la realidad parecen dibujarse en el ámbito académico argentino, donde constituyen y son constitutivos tanto de lo que podríamos denominar el ámbito del descubrimiento, conocimiento, saberes, así como de las trayectorias, 0 , mejor dicho, las carreras profesionales en lo que se denomina "la investigación", con éxitos disímiles entre los que se inscriben en uno u otro camino. 
Caracterizaremos como "investigación normal" por su carácter extendido y dominante, aquella que se produce y reproduce en las estructuras fuertemente formalizadas, donde conceptos y teorías aplicables a las realidades locales tienen, en general, su origen en lo que se puede denominar los maestros de las disciplinas, mayoritariamente provenientes de los caracterizados como centros de excelencia del saber: universidades y centros de investigación dominantemente americanos y europeos estrechamente vinculados con las grandes editoriales que alimentan sin crítica los saberes de nuestros maestros locales y el conjunto de discípulos sostenidos con becas de las agencias, universidades, fondos de programas.

Esta investigación normal, consume la casi totalidad de los fondos para investigación y formación, en tanto los miembros de las Comisiones Evaluadoras son tributarios de este estilo de investigación donde el éxito de las propuestas está asegurado por las líneas trazadas en el largo proceso de colonización que podríamos caracterizar como horizontal -, al interior de las disciplinas en Argentina.

Al otro estilo de búsqueda de explicación de la realidad lo denominaremos como de "crítica conceptual", compuesto por un conjunto de herejes que intentamos desafiar esos saberes estructurados, lo que nos lleva a la búsqueda de nuevas explicaciones a través de métodos, instrumentos, marcos teóricos y conceptuales. En general, el punto de partida es la crítica de los saberes operativos en el conjunto de la sociedad y la convicción, además, que esos saberes actúan como obstáculos epistemológicos en la posibilidad de una explicación acorde con las condiciones de existencia de nuestras poblaciones operantes en nuestras sociedades.

En el ámbito de la práctica social, los saberes, en distintos niveles de estatalidad, definen líneas de acción a través de programas, planes, políticas, que afectan de forma directa las condiciones de vida - y la vida misma - de grandes grupos de población. Los saberes del hacer de los funcionarios, siempre derivados de la investigación normal, es decir, de las teorías de las verdades indiscutidas, se transforman de un simple juego ético en la práctica profesional a dar curso y reproducir las formas más inhumanas devenidas de un orden social esencialmente injusto.

Empero, en ambos estilos investigativos hay que añadir ciertas prácticas bamboleantes entre uno y otro, según convenga a los comisarios del saber. Estos teóricos olvidan la riqueza inagotable de la realidad; y olvidan que toda cosa es una totalidad de momentos y de movimientos que se envuelven profundamente, y cada uno de los cuales contiene otros momentos, otros aspectos, otros elementos provenientes de su historia y de sus relaciones. Todo lo que proclama la superioridad de una parte sobre la totalidad proviene de la alienación y de sus formas modernas (Lefebvre, 1971, 2011).

La literatura académica hegemónica, en Argentina particularmente, y la investigación de base que la sustenta, independientemente de las distintas perspectivas teóricometodológicas, articula obstáculos epistemológicos (Bachelard, 1987) que cercan un saber cosificado centrado en ficticias dicotomías (centro/periferia; legal/ilegal; formal/informal; propietario/ ocupante; público/privado) que, al mantener 
como inobservable la génesis social del problema, redunda en la materialización fetichista de políticas reproductoras de la desigualdad social (Núñez, 2007, 2011, 2012; Roze, 2003).

En otros términos, se ha ido aludiendo, implícita o explícitamente, a un patrón espacial "centro-periferia", signado por un gradiente decreciente en las condiciones sociales, urbanas y de la intervención del Estado en medios de consumo social, proceso que se subsumió y denominó, junto al de la autoproducción de viviendas, como urbanización de la pobreza, sin suturar el hiato entre teoría social y espacio material (Roze, 1995).

Se trató, en la casi totalidad de los estudios urbanos latinoamericanos, de una ficción homogeneizante de sujetos desposeídos que viene promoviendo modelos acríticamente replicados de políticas desenraizadas de las prácticas sociales (Núñez, 2012). Esta naturalización y manera hegemónica de abordar el problema, ha permanecido hasta la actualidad y es realimentada por los organismos y las agencias internacionales, tiñendo los diagnósticos y justificando acciones que reproducen la desigualdad.

En ese contexto, del análisis de la literatura académica, independientemente de los momentos por los que atravesó y qué dimensiones se jerarquizaron, las distintas perspectivas pueden vincularse, en general, a partir de: a) un abordaje fragmentado y sesgado; b) una matriz analítica espaciotemporal decreciente centro-periferia en las inversiones (o ausencias) del Estado, a su vez reificado, ${ }^{3}$ en medios de consumo social; y c) los determinismos predominantes muestran la resultante, en la que las fuerzas han desaparecido, se han cosificado y transformado en inobservables, es decir, donde la tregua establecida por los sujetos aparece como el sistema institucional de ese momento: el orden, y, por ende, la política urbana como un producto de actores sociales previamente constituidos (mercado, Estado, empresas...), naturalizándola en apariencias fetichizadas (Cfr. Pírez, 1995; 2013). En otras palabras, y siguiendo a Elías (1982), se abandonaron las preocupaciones teóricas por el estudio de los procesos, tratando a los objetos sociológicos como entidades cerradas e independientes entre sí, omitiendo la conceptualización de las acciones y las relaciones sociales que vinculan dichos objetos, sólo sentidas en trabajos de campo de tipo etnográfico y análisis documentales, de largo aliento (Núñez, 1994, 2000, 2012). Siguiendo a Pradilla (2010, pp. 9-10), las visiones y políticas importadas y fragmentadas disciplinarmente, ha llevado a los investigadores a acuñar y reproducir conceptos (ciudad global, ciudad informacional, ciudad dual, ciudad estallada, etc.), que se generalizan y se reproducen acríticamente en cualquier parte del mundo, referenciando en forma espuria, en nombre de la globalización, homogeneizando procesos sociales e ignorando las particularidades socio-territoriales, escamoteando el análisis de la totalidad social como articuladora de la segregación y la fragmentación, sin dar cuenta de sus causas estructurales (Pradilla, 2010, pp. 16-17; Núñez, 2000; 2012).

En síntesis, nuestra crítica a la construcción dominante del problema que nos ocupa refiere a tres dimensiones: 1 ) una visión tecno-burocrática que constriñe los ejes del debate a la naturalización de la escasez, 
conduciendo la reflexión a la hegemonía de las obras; a materializar objetos, manteniendo la génesis del problema como inobservable (Cfr. Herzer, Pírez, et al., 1994); 2) aun los que propugnan observar los aspectos socio-políticos del problema, construyen la identidad social del demandante (Castro, 1999), perdiendo de vista que, por un lado, no siempre y no toda carencia material se transforma en demanda social (por qué y cómo, nos preguntaríamos), $y$, por otro, que la demanda y la apropiación de las respuestas a esa demanda es una de las formas en que la rutina burocrática, que descansa omnipotente e infinita sobre la propiedad parcelaria, dirá Marx (1998, p. 120), diluye, fragmenta y dispersa de esa manera la lucha social (Holloway, 1994; Lefebvre, 1972, 1976); y 3) a la ausencia del análisis sobre cuál es el contenido de la expresión de una lucha de clases como lucha política, económica y teórica (Marín, 1996).

En todo caso, la pregunta debería reformularse en términos de qué respuestas, a qué demandas y de quién y dónde, para poder desentrañar los mecanismos institucionales que operan en la construcción y ordenación normativa de lo que "debe demandarse". Concretamente, la desnaturalización de la demanda conlleva a no considerarla sólo un derecho, ${ }^{4}$ sino una condición esencial del funcionamiento de las instituciones y su burocracia (Holloway, 1994).

Sucintamente, el problema ha quedado encerrado en una naturalización y poco feliz esquematización que lo fractura en políticas, enraizadas en arreglos formales, y necesidades, enraizadas en arreglos informales (Cfr. Pírez, 2013), perdiendo de vista que todo límite, toda frontera es una relación social.
Se trata de reorientar la observación sobre el movimiento de la sociedad, para tornar observable que aquella ficción homogeneizante oculta un proceso previo de expropiación, por lo que debería hablarse de miserias de la urbanización (Núñez, 2012).

En efecto, ¿Cómo comprender, si no, el crecimiento en profundidad y extensión de los denominados asentamientos precarios, que en la ciudad de Mar del Plata superan los 200? ¿Cómo explicar que la tasa de crecimiento de la población que habita en esa forma social de extrema pobreza denominadas villas creció a un ritmo más de cuatro veces superior a la tasa de crecimiento de la población total? Avances de actuales investigaciones en distintas ciudades (Núñez y Ciuffolini, 2011), muestran que un alto porcentaje de los adjudicatarios de viviendas sociales no reside en ellas porque se han vendido hasta cuatro veces, y han retornado a otro asentamiento; un $48 \%$ de los hogares continúa sufriendo hacinamiento personal, un $24 \%$ padece hacinamiento familiar, se abandona el trabajo por los costos sociales y económicos que implica el traslado, pérdida de fuentes de ingreso, se producen rupturas de relaciones sociales y construcción de otras nuevas, muchas veces bajo la forma de conflictos de vección horizontal, cambios en los comportamientos demográficos, entre otras transformaciones. Es decir, las cifras e indicadores socio-habitacionales por todos conocidos, sólo reflejan este proceso expropiatorio. Se trata de conocer la génesis de los procesos que las generan, oculta bajo su naturalización.

Pero argumentemos más detenidamente nuestra exposición. A mediados de la década de 1970, concomitantemente con la crisis 
del modelo de acumulación fordista, se produjo una ruptura epistemológica en los estudios urbanos, a partir de la aplicación de análisis basados en diferentes enfoques del materialismo histórico. En ese marco, el espacio urbano se consideraba un componente de la producción y reproducción de las relaciones sociales capitalistas (Lefebvre, 1969, 1972, 1976); de las dinámicas más generales de la acumulación (Lojkine, 1979); y el locus de la reproducción de la fuerza de trabajo (Castells, 1978), ${ }^{5}$ siendo la renta del suelo la categoría explicativa de los diferentes costos de reproducción y de la división social del espacio (Lipietz, 1979; Topalov, 1979; Yujnovsky, 1984).

Así, los estudios urbanos latinoamericanos, en general, de la década de 1970 y comienzos de la de 1980, inscriptos en la corriente francesa de la sociología, movilizaron mecanismos estructurales y de naturaleza económica para explicar la conformación de la ciudad y las políticas urbanas, ya sea asociándolos al modo de producción o al comportamiento económico de los agentes sociales (Marques, 1997). ${ }^{6}$ A lo largo de la década de 1980, esos determinismos fueron reemplazados por otros de nivel micro, basados principalmente en los actores y los movimientos sociales (Castells, 1988). ${ }^{7}$

En ambos casos, coincidimos con el análisis de Marques (1997) en que el punto ciego de la literatura fue el análisis del Estado, en toda su complejidad, y, por ello, las políticas urbanas eran explicadas como un producto de procesos externos a él, predeterminadas por las necesidades de reproducción del sistema capitalista, basando las reflexiones, primero, en los procesos localizados del lado de la oferta $y$, posteriormente, del lado de la demanda, reificando, en ambos casos, el producto, el Estado y el mercado.

A partir de la década de 1990, las políticas de ajuste neoconservador, bajo denominaciones como la mercantilización del consumo, la desregulación del mercado, la privatización de los servicios, la reforma del Estado y la descentralización, entre otros procesos, colocaron los problemas urbanos de manera muy diferente a las dos décadas anteriores, y reinsertaron como principal tema de investigación en las ciencias sociales, la problemática del Estado, que había sido desplazada en la década de 1980 por estudios sobre la democracia y la sociedad civil.

Sin embargo, y coincidiendo con Oszlak (1997), buena parte de esa literatura ha omitido aspectos significativos, al evaluar procesos de reforma sobre modelos de Estado deseables (Cfr. Herzer, et al., 1994).

Asimismo, los programas de modernización del Estado y descentralización, preconizados e impulsados por los organismos multilaterales de crédito, a través incluso de cursos de gestión urbana impartidos a través del mundo (Stren, 2001, p. 10), y aceptados e implementados por nuestros académicos y gobiernos de la región, se alimentaron de dos procesos: 1) la revalorización del municipio; y 2) las privatizaciones. ${ }^{8}$ Concretamente, "Ciudades y municipios son la base de la estructura política de cualquier país democrático" (Freire, 2001, p. xx); "En algunos aspectos importantes, un gobierno local es análogo a un negocio. Proporciona servicios a sus clientes, los residentes. A su vez, los residentes deben pagar por los servicios que reciben" (Bird, 2001, p. 164), o "...el 
lenguaje de 'reinventar el gobierno', y aplicar las experiencias y cultura del sector privado al gobierno local (...)comenzó a tener coherencia (...) los administradores locales (con el apoyo de agencias internacionales tales como el Programa de Administración Urbana, UNCHS, UNDP y el Banco Mundial) comenzaron a llamarse "administradores urbanos" (Stren, 2001, p. 188).

En ese contexto, la política urbana y el Estado van a reaparecer, en los estudios urbanos, pero acríticamente naturalizados bajo el término de gestión, ${ }^{9}$ especialmente de los medios de consumo colectivo, ${ }^{10}$ y la globalización (Pradilla Cobos, 2009, 2010), abonando lo que hemos dado en llamar las miserias de la urbanización, a los efectos de conceptualizar la imbricación de la mercantilización política, económica y teórica, a la vez que problematizar, en una irónica inversión, la construcción de la tesis hegemónica de urbanización de la pobreza (Núñez, 2007, 2012).

Precisamente, las perspectivas del estudio de las ciudades - asumiendo que las usinas del pensamiento dominante en los ámbitos académicos latinoamericanos se importan de los centros de saber de las metrópolis -, refieren al dominio de la reflexión sobre las metrópolis latinoamericanas, donde, al calco de los estudios de las ciudades globales, dejan de lado el conjunto de ciudades de porte medio que alojan, en general, la mayor parte de la población de América Latina. Resulta imposible explicar - con las conceptualizaciones e instrumentos de análisis con que se enfocan los problemas metropolitanos -, los fenómenos que impactan, configuran y estructuran las ciudades intermedias latinoamericanas, producto de la aplicación de los planes y proyectos de las políticas neoliberales. No se trata de lo mismo a otra escala, sino de problemas y fenómenos propios del tipo de configuración que la relación de la ciudad con su entorno, así como la dinámica de las clases populares, determina.

La ciudad informacional, los barrios cerrados de las burguesías aterrorizadas por la sociedad que están creando, los shoppings, ciudades mundiales, las megaciudades, los archipiélagos urbanos... nos entretienen en juegos de nuevas palabras, para mirar una ciudad sin detenernos en los sujetos. En palabras de Balvé y Balvé (2005, p. 128), "el fetichismo de los cuerpos y las cosas organizadas en instituciones corporizadas, sean éstas sindicatos o movilizaciones, se convierte en un obstáculo epistemológico en el proceso de conocimiento de la realidad".

La ciudad, ámbito de enfrentamientos, lugar de relaciones, espacio de conflictos, alianzas, estrategias de supervivencia, se ha convertido en lugar describible en una práctica de entomólogos. Como los "no lugares" la "no ciudad".

Esa no ciudad es la ciudad sin multitudes. Es la ciudad que el pensamiento posmoderno funda y refunda todos los días en sus ilusiones de una sociedad sin trabajo, sin masas, sin clases, sin sujetos. Nuestra ciudad latinoamericana es la antítesis, y entenderla es nuestro rumbo.

Nuevos fenómenos, son los emprendedores en Pymes ${ }^{11}$ que se expresan en le retorno al paisaje urbano de vehículos de tracción a sangre, particularmente carros tirado por caballos que circulan a lo largo del día por las calles céntricas de la ciudad 
en busca de objetos vendibles, madera para combustible, cartón, botellas, etc.

Las más avanzadas redes de la ciudad informacional, que vinculan (y hacen parte de la globalidad) a la mayoría de la población tienen su nodos en las agencias internacionales de crédito y llegan a los usuarios a través de programas de distintas instancias de la estatalidad bajo la forma de de reparto de cajas de comida, alimentos en comedores escolares, y comedores comunitarios $\mathrm{y}$, en los últimos años, tarjetas de débito, popularización de los cajeros automáticos, como forma de pago de diversos planes y programas sociales.

Así, la ciudad informacional y las Tecnologías de Información y Comuncaciones se nos aparecen en nuestro centro con una notable cantidad de gente con teléfonos celulares; los bancos y sus redes de cajeros automáticos, comercios de artículos de computación, cabinas de telecentros, una gran empresa de servicios de computación de capitales mixtos y sin que quede mucho por enumerar los usuarios privados que intentamos ser intelectuales globalizados.

La mayoría de las escuelas han sido equipadas con computadoras, pero muchas de ellas no tienen electricidad o no pueden pagar maestros que enseñen computación a los chicos, o las maestras, lejos de la cultura informática prefieren que no se toquen para que nadie las rompa.

Tal vez, el único elemento que refleja grandes avances en la cultura mediática son los políticos y gobernantes, quienes han construido una virtualidad de su imagen y de sus emprendimientos mientras más de un tercio de la población está por debajo de la línea de indigencia.
Desde la perspectiva urbanística y/o arquitectónica los nuevos espacios de sociabilidad urbana lo constituyen los comedores comunitarios o los nuevos asentamientos donde aparecen espacios comunes para la alimentación de los caballos. Lo que queremos poner de manifiesto son dos cuestiones: la primera, ya señalada, sobre el uso de las categorías analíticas en las modas sociológicas. La segunda, y más importante, que afuera de los circuitos globales de la información y el dinero, los comportamientos de los sistemas siguen leyes diferentes, de modo que debemos repensar la dinámica de nuestras ciudades a partir de nuestros hallazgos empíricos y emprender la aventura de teorizar por nuestra cuenta.

Nuestra propuesta es poner en interacción y movimiento los vínculos que vertebran tales relaciones, indisolubles al hablar de política urbana; tornando visibles los procesos de construcción social de identidades ${ }^{12}$ situándonos, para ello, en una perspectiva diferente que abra el problema, y partiendo de otra pregunta rectora preliminar ¿qué relaciones sociales se ocultan, se construyen y destruyen, detrás de la materialidad de los objetos? ¿Qué mecanismos de violencia invisible y cotidiana operan detrás de la racionalidad técnico-burocrática de una política urbana, y a través de qué dimensión institucional? Así, la política urbana que viene siendo reificada en una aparente homogeneidad como producto, nuestra hipótesis de trabajo la repiensa como materia prima analítica de las interconexiones en las prácticas cotidianas de dominación, y como mediación de relaciones sociales. ${ }^{13}$ 
En otras palabras, transformamos lo que se denomina política urbana, en luchas sociales, desnaturalizando así la cosificada relación lineal entre "población que aumenta, una ciudad que se expande y objetos escasos que, corriendo detrás, nunca llegan..."

$Y$ esto es lo que permitiría situar el conflicto en el conjunto de la sociedad, en la lucha de clases, ya que la producción de lo social es ininteligible sin introducir la noción de confrontación, de enfrentamiento, de luchas entre existencias...Se ponen en interacción, así, obediencia y resistencia como los vínculos que vertebran el conjunto de relaciones entre clases; de relaciones sociales entre sociedad y espacio.

\section{Abriendo categorías}

Cuando hablamos de política urbana, una primera dimensión es el Estado. Pero " ¿Se puede analizar el Estado?", se pregunta Lourau (1980, pp. 24-25). La premisa básica es que sí es posible analizarlo pero, a partir de ahí, lo que aparece son estudios, de las distintas alternativas, de reificación de un determinado Estado del poder (Lourau, 1980).

Está ausente, diría este autor, en las interpretaciones corrientes, el análisis sobre cuál es la fuerza que dispara, autoriza o legitima la modificación de las relaciones sociales que condensan esa estabilización. Pareciera confundirse, en general, el resultado de la lucha con lo que el contenido de la lucha transforma. Porque esa "emergencia" es, en todo caso, la expresión de una lucha de clases como lucha política, económica y teórica.
Expresión, más o menos densa, en alguno de esos ámbitos centrales, pero nunca en forma escindida (Marín, 1996).

Así, la perspectiva cambia si consideramos, como dice Lourau (1980, p. 123), que es el Estado el que nos analiza, el Estado es nuestro inconsciente, a partir de un enfoque que propone reflexionarlo no sólo como objeto sino como instrumento de investigación (el proceso de estatalización), es decir, abrirlo, transformarlo en un instrumento de conocimiento de las fuerzas reales que operan no sólo en el control sino en el proceso de construcción del orden social y, por lo tanto, de identidades sociales que lo sostienen y reproducen (Roze, 2001b, 2003b; Castro, 1999), porque:

El Estado es una simple película de legitimación sobre la superficie de las sociedades (...) El Estado es el Inconsciente... (Lourau, 1980, pp. 15-19)

Porque así pareciera ser la forma en que el Estado se nos revela en Marx y Engels, como una organización compleja, atravesada por conflictos y luchas:

Todas las luchas que se libran dentro del Estado (...) no son sino las formas ilusorias bajo las que se ventilan las luchas reales entre las diversas clases... (Marx y Engels, 1968 , p. 35)

Esta visión dinámica permitiría articular teóricamente lo que se presenta en distintos niveles de abstracción, considerando al Estado como un conjunto dinámico, cambiante, y conflictivo de relaciones entre clases, en una determinada sociedad, que expresan la dominación bajo formas aparentes de 
consenso, y a los aparatos del Estado como la forma visible en que esta relación se materializa (Roze, 2003b). Distinción útil, y necesaria, diría el Profesor Paul Bromberg, entre Estado y aparatos del Estado, que permite claridades que, de confundir los términos, no serían posibles ${ }^{14}$.

No conocemos, hasta el momento, mejor operacionalización para avanzar y sortear estériles discusiones, y que nos ayude a analizar las interconexiones en las prácticas cotidianas de dominación, naturalizadas en apariencias fetichizadas. Concretamente, creemos más fructífero empíricamente y más fértil teóricamente, analizar los mecanismos institucionales que dispersan, diluyen y fragmentan la lucha de clases, considerando al gobierno como el uso de esos mecanismos, en el que compiten los partidos que expresan, alternativamente, las fuerzas orgánicas propias del capitalismo (Roze, 2003).

Empero, esas instituciones deben ser leídas como construidas por fuerzas sociales para librar las confrontaciones de las clases dominantes; instituciones políticas e instituciones sociales (Marín, 1996), como ámbitos del régimen, es decir, de los defensores del orden social y jurídico institucional (Roze, 2003b), a través del interjuego por el cual se intenta mantener el dominio de los intereses de una clase sobre el conjunto.

Las formas en que se organizan estos intereses sociales y económicos particulares desde la dominación capitalista, pueden ser mejor comprendidas a través de Marx (1968, pp. 59-61), cuando esclarece las relaciones entre burocracia y corporación:
"Las corporaciones son el materialismo de la burocracia y la burocracia el espiritualismo de las corporaciones. La corporación es la burocracia de la sociedad civil; la burocracia es la corporación del Estado";

y más adelante,

"La burocracia (...) es la 'conciencia del Estado', la 'voluntad del Estado', el 'poder del Estado'... "La burocracia es el círculo del que nadie puede escaparse

Así, esa dialéctica se va a explicar a partir de la transfiguración de los intereses (particular y general) y, en esta crítica, la burocracia, como institución de obediencia pasiva, sería una forma de incapacidad para la lucha.

La inversión del problema que proponemos reconoce su origen en que "No existe inicialmente un sujeto, al que se ve, se nomina, se analiza, y finalmente sobre el que se despliegan un conjunto de acciones (de salvaguarda, de protección, de represión, de exclusión, etc.) sino que las acciones que la sociedad ejerce y los procesos de conceptualización con que se nominan, son los elementos configuradores del sujeto, resultante de esas acciones", en Roze et al. (1999) y Roze (2003).

Es decir, postulamos que creando, manipulando y violentando identidades que sustentan un orden permanentemente naturalizado, se genera y nomina población cautiva, objeto de diversas expropiaciones, a través de distintas formas de violencia, deambulando por la espacialidad social que se configura en una doble dimensión: una estatalidad profunda y una estatalidad extensa 
(Núñez, 2012) ${ }^{15}$. ¿Qué lazos sociales y políticos articulan la estatalidad profunda, (el blindaje ${ }^{16}$ hacia su interior), y la estatalidad extensa, su permeabilidad hacia y con el exterior? ¿Cómo median las obras en la construcción/ destrucción de esos lazos? Porque, como dice Marx (1968, pp. 61-62):

El espíritu general de la burocracia es el secreto, el misterio guardado en su seno por la jerarquía y hacia fuera, por su carácter de corporación cerrada(...), es la lucha por los puestos más elevados; hay que abrirse camino (...) El burócrata ve en el mundo a un simple objeto de su actividad.

Esta apertura del problema nos permite salir del círculo vicioso de la tesis hegemónica de que hay sujetos pobres que se localizan en suelos baratos, sin servicios de infraestructura, en ausencia del Estado, desconociendo que su fuerza radica en poder disimularse $y$, por ende, es esa ficción homogeneizante de sujetos desposeídos lo que permite, precisamente, la acción racionalizadota y justificatoria de los aparatos del Estado y los intelectuales a la moda. En otros términos, la escasez de equipamiento urbano evidencia el enfrentamiento de las fuerzas sociales ${ }^{17}$ en la apropiación de la ciudad y no la ausencia del Estado (Pereira, 1986).

Ahora bien ¿cómo operacionalizar este andamiaje teórico? A partir de mediciones cruciales, por medio de las cuales se hace referencia a momentos del proceso social de enfrentamientos, donde emergen los problemas devenidos del juego de intereses, que se expresan tanto en sus aspectos económicos, políticos como teóricos (Roze, 2003).

\section{Mediciones cruciales, pseudonecesidades y pseudoidentidades}

Los estudios sobre política urbana, en general, han abordado los vínculos y las relaciones entretejidos entre los sujetos involucrados como algo dado, cosificados, y con un énfasis excesivo en la corrupción y en el clientelismo, ambos en sus variadas formas, reificando la burocracia, los vecinos y las empresas, en términos de actores y escenarios. Por otra parte, aun cuando el municipio ha sido el ámbito social clave de las políticas neoliberales, vehiculizando las reformas estructurales emanadas de los organismos internacionales de crédito, se ha prestado poca atención a las formas que asumen las alianzas de las fracciones sociales dominantes locales, y sus acciones, en tanto fuerza política que viabilizó el programa neoliberal.

Por el contrario, las mediciones cruciales (Roze, 1993; Núñez, 2012) refieren, por un lado, a distintos ejes de análisis: a) a las luchas sociales generadas en el proceso de construcción de estructuras organizacionales y su transformación (lucha política); b) a las luchas sociales entre fuerzas progresivas y del régimen (lucha teórica); y c) a las luchas sociales interburguesas (lucha económica).

En tanto a) hace referencia a la creación de instituciones políticas, b) y c) a instituciones sociales, que son atravesadas transversalmente por a) y, por lo tanto, suponen también momentos diferentes de articulación de alianzas de clase y de confrontación (Marín, 1996). 
Por otro, a distintos ámbitos de análisis, que interrelacionamos y abrimos: a) el ámbito político burocrático, el de cómo los sujetos definen situaciones de dominación y violencia a través del manejo de las instituciones, de la construcción de normas y de pseudoidentidades que generan población cautiva y excluida, de los dueños del saber y del hacer no se sabe cómo, dueños de las decisiones sobre las condiciones de vida de la mayoría de la sociedad, donde se organizan los intereses económicos y sociales particulares de la condición de dominación capitalista, el de los saberes legítimos, dominantes, que definen el orden de las personas y las cosas; b) el ámbito de la economía, de donde se construye la escasez de recursos económicos y se decide la transferencia que una parte de la sociedad realiza a otra; c) el ámbito de lo barrial, de identidades heterogéneas que oscilan entre la autonomía y la heteronomía, entre el consenso y la indefensión; la obediencia pasiva a la burocracia y la desobediencia; sus fracturas y controversias; y d) el ámbito de las empresas constructoras y su relación con el gobierno, los trabajadores y los vecinos, y la transfiguración de personificaciones.

El anclaje empírico del trabajo, a los efectos de ejemplificar la brecha entre teorías y realidad de la investigación que denominamos como "normal", lo constituyen las luchas por y con el agua y el saneamiento, en Mar del Plata, y la construcción de defensas, en torno a las inundaciones, en Resistencia, ${ }^{18}$ reconociendo que esta selección de dicho anclaje tiene su fundamento no sólo en la potencialidad teórico-metodológica y empírica para sostener nuestros argumentos, sino que constituyen dos políticas urbanas reconstruidas históricamente por los autores de este texto, pues atraviesan axialmente las condiciones de vida de nuestras sociedades.

El punto de partida fue, en el primer caso, comprender la génesis urbana como un momento de la lucha de clases; como forma de resolver un conflicto interburgués, a través de un intercambio de favores y la emergencia del pueblo como un loteo privado aprobado por excepción en 1874 (Núñez, 1994, 2012), pero instaurando la mercantilización del suelo urbano y el orden de la propiedad privada. De aquí se construirán socialmente las pseudoidentidades de ocupante, clandestino, usurpador y otros.

En ese desenvolvimiento, la génesis de una institución política como Obras Sanitarias de la Nación, en 1912, fue la forma de resolver un conflicto entre la Iglesia, los higienistas y la estatalidad, pero instaurando los límites del derecho al agua, creando las pseudoidentidades del usuario y el demandante. La bifurcación temporal de la manipulación de esta institución política por las diversas alianzas de clases que se la apropiaron, las fueron traduciendo en distintos dispositivos urbanos, tales como grifos públicos, bombas manuales, bombas eléctricas, etc. (Gráfico 1).

En el marco de la confrontación histórica sobre la gestión del agua y el saneamiento de fines de la década de 1980, paradójicamente, el proceso de municipalización ha quedado relativamente soslayado en la literatura especializada, respecto del derrotero que han seguido las diversas formas de privatización. Además de esa invisibilidad, nuestra crítica refiere a que, por un lado, en la bibliografía consultada, aparece el momento de la 
privatización y el estudio de ese proceso en términos de condiciones y/o consecuencias del mismo, desde un enfoque, en nuestra opinión, parcial, aun desde perspectivas teóricas diferentes. Particularmente en Argentina, a pesar del lugar de privilegio en que las investigaciones en ciencias sociales ubicaron a los servicios públicos en la década de 1990 , lo hicieron de una manera fragmentaria y sesgada, obstaculizando la mirada de una década aludiendo al paso de un servicio bajo control público, a un servicio privado no regulado. Se afirmaba que "las correas de transmisión entre uno y otro polo (públicoprivado) pudieron accionar por las usinas de pensamiento neoliberal, por una estrategia de cooptación y soborno al sindicato" (Loftus y McDonald, 2001) y "por la ausencia de la sociedad en el proceso de discusión" (Aspiazu y Forsinito, 2001). Se ignoraron, así, los observables que le otorgarían significación al proceso, al considerar la privatización como un punto de partida y de llegada, subsumiendo su complejidad en las precondiciones, condiciones y consecuencias de la participación del capital privado. Sin embargo, ni la sociedad ni el sindicato estuvieron ausentes en el conflicto por la transferencia de los servicios, iniciado antes de 1980. En ese marco, la municipalización del servicio de agua y saneamiento fue una forma de resolver un conflicto de cuatro años entre gobierno y sindicato, que emergió como lucha económica, generando amenazas, chantajes e indefensión a las fracciones sociales excluidas de esa confrontación, bajo la forma de "falta de agua" (Núñez, 2007, 2012).

Siguiendo el Gráfico 1, lo que se conoce como OSN fue una sucesión histórica de distintas alianzas de clase que crearon, se apropiaron, manipularon y transformaron una institución política para vehiculizar sus intereses a través del agua y el saneamiento, construyendo y transfigurando distintas identidades sociales (Núñez, 2007, 2012).

Con esta mirada teórica, genética y procesual, pudimos tornar observables procesos históricos que trabajos sobre los servicios públicos soslayan, y que explican, precisamente, una política urbana, de los cuales mencionaremos sólo algunos: a) la creación del cerco urbano, de mediados de la década de 1930, que por ley limitaba espacialmente el espacio escaso para la inversión pública de agua, condicionando la demanda legítima, y por fuera del cual, por supuesto, la población comenzó a desplegar una multiplicidad de estrategias de resistencia y de apropiación del agua. Estrategias de desobediencia al cerco, dentro y fuera de él, porque el límite no significó la inversión efectiva. Esto no es sino la construcción estatal de la carencia, ${ }^{19}$ de población cautiva, que luego será clasificada y homogeneizada, entre otras nominaciones, como clandestina, sujeta a nuevas expropiaciones; b) el ANDA, que ya en 1944 transforma el servicio público en una ficción, ${ }^{20}$ c) la $A G O S N,{ }^{21}$ que intenta vincular el adentro y el afuera del cerco con extensiones atravesantes que supusieron relaciones de propiedad y buena vecindad, para confluir en usuarios; d) en 1956, el primer proyecto de privatización de OSN, cuando Argentina ingresa al FMI y al BIRF, con la consiguiente apertura al capital financiero internacional, ${ }^{22}$ derivando en la creación del SNAP (1964), ${ }^{23}$ donde la alianza con la burguesía extranacional va a permitir a los 


\section{Gráfico 1 - Eje temporal de las bifurcaciones de OSN}

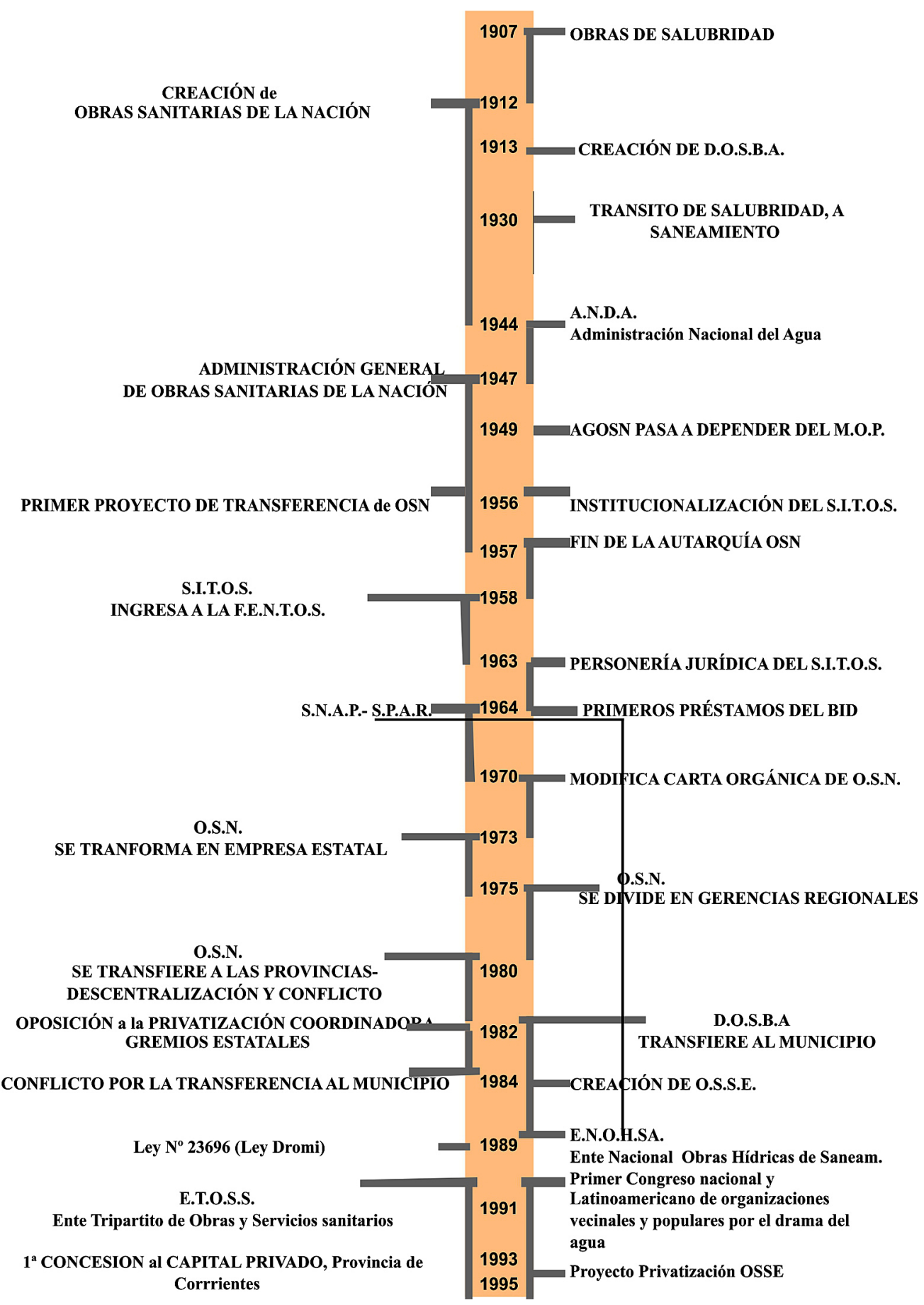

Fuente: Núñez (2007). 
organismos internacionales conocer dos cartas fundamentales para el juego privatizador de 1990: ${ }^{24}$ las constituciones provinciales y los recursos hídricos subterráneos y superficiales de todas las provincias, neutralizando a otras fracciones sociales a través de un tortuoso camino a la propiedad y al agua, según capacidad de pago, e indefensión. Indefensión que se profundiza a partir de perversos procesos de construcción de heteronomía, obediencia pasiva y anticipada, y subordinación.

En lo que denominamos estatalidad profunda, hay que entrar en el espacio social de la burocracia de la clase dominante para encontrarnos con: la migración de recursos y conocimientos, técnicos y financieros, entre instituciones; la seducción, captura, migración y desecho de técnicos y funcionarios entre instituciones, y entre éstas y empresas constructoras; apropiación de cargos jerárquicos a partir de las prácticas heteronómicas de los partidos políticos; intercambio social clandestino entre el espacio público y el espacio privado (colusión); absorción gradual y continua de intelectuales orgánicos; lealtades que reproducen la obediencia anticipada y subordinada; funcionarios cautivos de los ilegalismos, intermediarios de la alianza entre el gobierno, las empresas y la universidad, entre otros vínculos. En otros términos, los lazos de lo que denominamos territorialidad burguesa.

A su vez, la heterogeneidad empresarial materializada en el territorio, expresa un conjunto de relaciones sociales que nos hablan de una ficción jurídica de igualdad en las licitaciones. Algunas de ellas refieren a la permeabilidad gobierno-empresa; la terciarización interempresarial; la asociación partido-empresa; la asociación inter-empresarial; la cartelización. Estas relaciones, que nos hablan nuevamente de la complementariedad y los difusos límites entre lo legal/ilegal, entre corrupción y colusión, nos abren los vínculos con los vecinos quienes, también, desplegarán una multiplicidad de estrategias, en defensa de sus condiciones de reproducción, resignificando constantemente esa identidad, al combinar, en sus acciones, distintas personificaciones. Es decir, los vínculos de la estatalidad extensa.

¿Quién y cómo construye la demanda? ¿Cómo se establece el juego entre vocero y representados? ¿Cómo se traduce este juego en la relación con el campo político y hacia adentro del campo barrial, en una política urbana? ${ }^{25}$

A veces, el vecino legítimo, opera como intermediario entre quien no tiene la propiedad del suelo y la empresa pública, y construye solidaridades, intercambiando capital económico por el trabajo del vecino pauperizado. Concretamente, es el vecino legítimo que personifica la empresa, a la vez que articula acciones para la valorización económica y social del barrio, siendo también, un promotor. Otras veces, la estrategia de cartelización de las empresas, permite entablar negocios con el vecinalista, dando lugar a la colusión y desplazando a la institución política. Es decir, es el vecino legítimo, dirigente barrial, que puede ser corrupto, y personificar a la empresa estatal, eludiéndola.

Esto lleva a profundizar la fractura vecinal debido a que los costos se inflan, llegando a la denuncia, de otros vecinos, de la falsificación del contrato vecino-empresa. 
En otros casos, se induce al vecino moroso a que arregle con el abogado de la empresa constructora. Entonces, el vecino corrupto, se transforma en persuasivo legítimo de aquellos a quienes introdujo en un conflicto legal ilegítimo, en función de sus intereses particulares, personificando la legalidad.

Claro está que, otros vecinos, están nutridos de valores diferentes. Son los vecinos legítimos que, sin cuestionar la heteronomía, están apegados a lo instituido y a la moral de la palabra, como capital simbólico, personificando al peticionante obediente pasivo. Pero la construcción compleja de la heteronomía a través de la palabra, de la promesa, crea el vecino capturado por el discurso del gobierno, que se lo apropia y reproduce, entrando en el juego del campo político-burocrático, aun en condiciones de máxima precariedad. En estos intercambios, juega la imagen fetichizada del vecino de creer que pertenece, por un momento, al estado del poder. Es el vecino cooptado, personificando un inspector, ocupando el lugar de un técnico, desplazado a su vez, por el funcionario.

La contracara, es la fracción social que se opone a las obras, obstaculizando la urbanización, pero, a la vez, realimentando el desenvolvimiento de otras estrategias, apropiándose de la potencial renta diferencial y de la valorización económica y social del barrio, aportada por otros vecinos. Nos referimos al vecino ausente y el vecino terrateniente.

También, la desocupación del otro, su estigmatización, se transforma en moneda de cambio que permite optimizar las propias estrategias de acumulación de capital económico. Es el vecino legítimo que personifica la autoridad legítima, desplazando a las empresas constructoras: "que trabajen los desocupados del barrio..."

En fin, las identidades sociales que configuran las acciones en una política urbana, aparecen constantemente resignificadas. Las personificaciones son trastocadas y generan creencias que redefinen interacciones, vulneran relaciones sociales pre-existentes y constituyen nuevas. En otras palabras, ejerciendo una violencia simbólica.

Los vecinos confían más en un organismo del Estado conducido por políticos, que en un procedimiento autogestionario conducido por sus propios vecinos... (Entrevista a Carlos Katz, ExPresidente de la empresa municipal de agua)

Esta aterradora conclusión de un funcionario, ganado por la ignorancia, sólo puede apenas comprenderse en el contexto de la compleja construcción de la heteronomía que hemos intentado objetivar, es decir, la construcción de la argamasa de violencia y obediencia en la que se anclan las situaciones de dominio de una fracción social, sobre el conjunto.

De esta manera, se reproduce el discurso oficial y se devela la función negada de las instituciones y reproduciendo el orden dominante.

Si en el caso de los servicios públicos hemos visto cómo la vaporosa indefinición de la estatalidad profunda y extensa explica la provisión selectiva de agua y saneamiento, en el caso de las defensas contra la inundación la explican como una pseudonecesidad. ${ }^{26}$

Acuñamos ese término a los efectos de escapar de los encierros que nos planteaban los conocimientos que la ciencia normal había 
construido como "saberes" alrededor de las inundaciones.

Desde la ciencia normal se hacían presentes cuatro saberes vinculados con "lo social" - más allá de las "exactitudes" de los saberes técnicos o los haceres de los saberes de la decisión - que buscaron aportar a la cuestión. Referían a: 1) la evaluación socioeconómica, 2) las estadísticas sociales, 3) la etnografía de la prensa, 4) el saber en auxilio de la reparación. Todos ellos, con un fuerte acento de lo local, por lo que, a partir de la trascendencia de la catástrofe en 1982-983, nuevamente el saber experto, hegemónicamente concentrado en Buenos Aires, se traslada a prestar colaboración, bajo la forma de un equipo de la Comisión de Estudios Urbanos y Regionales, del Consejo Latinoamericano de Ciencias Sociales CLACSO.

Con algún financiamiento, con el prestigio y el saber de la corporación latinoamericana y el esfuerzo de los intelectuales locales, - que prestan su información a cambio de alguna participación - se organiza el Saber, con mayúscula, que en última instancia no fueron sino las teorías de los países del norte, prolijamente traducidas y aplicadas a la situación local (Cfr. Caputo, Hardoy, Herzer y Vargas, 1985; Caputo y Herzer, 1987; Herzer, 1990). Lo más sobresaliente de las conclusiones del seminario fueron que "cuando más débil es la estructura política, económica y social de una sociedad, mayor es el impacto de la catástrofe" (Diario Norte, viernes 20-5-1983, p. 4).

Ante tanta pobreza conceptual en relación con el fenómeno, estudiamos para cinco situaciones de catástrofes, las acciones, sus resultados y consecuencias llevadas adelante tanto por las poblaciones como los diversos aparatos institucionales para enfrentar las consecuencias del desborde de las aguas del Río Paraná.

Acciones codificadas, repetitivas, que a lo largo del período permanecen, se modifican, o son reemplazadas por otras -, de cómo plantear y resolver los problemas derivados del fenómeno natural del desborde de los ríos.

Estas acciones produjeron una parte de lo social, produjeron sujetos, produjeron individualizaciones; produjeron el inundado, como identidad, como cuadrícula de sujetos cuya conducta se nutre de sus estrategias de supervivencia y aquellas esperadas por quienes se asumieron dueños del saber de lo público.

Catástrofe y encierro, sintetizados en el albergue, fueron los elementos que determinaron el ámbito de la manufactura de esta identidad, el lugar donde se hicieron observables y observadas las cotidianeidades de la pobreza.

Hemos privilegiado y particularizado los procesos de conocimiento, reflexionando sobre el saber de las inundaciones. Hemos mostrado que es una larga construcción, producto de la diseminación social de un conjunto de pensamientos perversos de quienes tuvieron la hegemonía del discurso.

Quienes tuvieron y tienen la decisión y el saber para paliar sus efectos, han fundado su acción en un conjunto de falacias que estructuraron socialmente una pseudonecesidad.

Dicha pseudonecesidad, a lo largo de más de 50 años de enfrentar el problema, tomó 
la forma de la imperiosa necesidad de construir un rígido sistema de defensas materializado en obras. Así, las falacias que la sustentaron fueron tres: 1) las defensas como única alternativa, 2) que no hay otro saber que el saber técnico, 3) que no existen soluciones surgidas de lo local.

Respecto de la primera, la concepción de las defensas definitivas de la ciudad de Resistencia, planteadas como un gigantesco recinto producto de un conjunto de grandes obras, constituyó desde su concepción un obstáculo a pensar otro tipo de alternativa y bloqueó toda forma de reflexión acerca de la ciudad.

La necesidad de defensa se ha constituido como una necesidad "natural" para la existencia de la ciudad de Resistencia.

Transformar una cuestión propia de lo social en "natural" conlleva, entre otras conclusiones, a su inevitabilidad, así como también a hacer inobservable su origen, ya que por su naturaleza, se ha generado con la propia ciudad.

La primer falacia - la más difícil de refutar - es acerca de la necesidad misma de defensas.

¿Para qué las defensas? El primer señalamiento que queremos hacer, es que la concepción de defensas definitivas, actuó como una profecía que se autorrealiza. Desde el momento que se planteó que si no se construían defensas definitivas Resistencia agonizaría con las inundaciones, se pusieron en marcha mecanismos que hicieron de los desbordes una catástrofe o se impidieron que se pusieran en marcha los mecanismos autocorrectivos propios de una estructura sistémica (García; Inhelder, Volnéche, [1977]) ¿A qué nos estamos refiriendo?
La ciudad sin defensas, hubiera autoorientado su crecimiento hacia las zonas sin afectación; ya por los mecanismos propios del mercado, o por las decisiones de los técnicos que necesariamente deberían orientarse hacia las zonas altas.

Sobre la falacia de que no hay otro saber que el saber técnico, vimos que a la par del despliegue del saber técnico de controles estructurales de las inundaciones y de cualquier otro tipo de catástrofe a través de grandes obras, se fueron desarrollando un conjunto de saberes respecto de la prevención de la catástrofe vinculados con la introducción de acciones racionales en las acciones de control de asentamientos, en la construcción de edificios, en el tratamiento de los territorios como las llanuras inundables.

La emergencia de estos saberes, fueron producto, particularmente, de las consecuencias no buscadas de las grandes soluciones que constituyeron paradigmas del saber tecnológico en el control de la naturaleza, como lo fueron las grandes obras hídricas de la cuenca del Rió Mississippi y los grandes ríos de los EE.UU. ${ }^{27}$

Emergieron, también, de la búsqueda de soluciones en situaciones donde los ingentes gastos en grandes obras constituían una utopía y las soluciones debían buscarse con procesos de adecuación a los fenómenos naturales.

Esos conocimientos, no fueron privativos de unos pocos, sino que se plantearon como patrimonio de la humanidad, a través de los organismos internacionales. El saber técnico respecto de las catástrofes no puede ignorarlos, alegando algún tipo de aislamiento o dificultad de acceso a la información. La 
orientación del saber es una elección. Lo universal apareció de la mano del lucro de los consultores, y se instaló dejando de lado toda otra alternativa. Esa situación aún es presente.

Por último, la falacia de que no existen soluciones surgidas de lo local. Otra vertiente posible como respuestas a las inundaciones a lo largo de este período de recurrencia, fue la emergencia de los saberes locales, como resultado del ingenio, la acción o la práctica de los afectados, o como preocupación intelectual de los técnicos atentos a nuevas alternativas frente al fenómeno.

Soluciones improvisadas (colocar ropas y utensilios en grandes bolsas plásticas semi infladas que flotan, haciendo posible transportar grandes volúmenes de ropa y víveres con el agua en la cintura); artefactos producto de la improvisación y el ingenio (mecánicos que construyeron para campos inundados lanchones adecuados a los niveles de la zona, botes con gomas de autos o tractores, o transportes acuáticos construidos en base cualquier otro material de desecho), pequeñas defensas para impedir la entrada de agua en las casas, sistemas caseros de bombeo, no fueron sino anécdotas locales.

Respecto de las soluciones alternativas de técnicos locales, tampoco tuvieron eco aquellas propuestas que tuvieran otro punto de partida que los grandes emprendimientos. ${ }^{28}$

La posibilidad de defensas por áreas, la necesidad de establecer códigos para la construcción, la posibilidad de tecnologías adecuadas a las áreas inundables de las costas y de las islas, inclusive, la solución de situaciones límites en cuanto a desagües siempre críticos con trazados a cielo abierto, no alcanzaron siquiera existencia efímera.
Una solución a las inundaciones rurales, propuesta en el mencionado seminario que consistía en que los productores instrumentaran sistemas locales de defensas, pequeños terraplenes que podían ser realizados con sus máquinas o de sus vecinos, quedó como una anécdota de intelectuales y de expertos agropecuarios encerrados en sus experimentos. (Neif, Patiño y Orfeo; 1987).

\section{Reflexiones finales}

Desde el momento mismo que, en 1999, pusimos en marcha el grupo de trabajo sobre ciudades latinoamericanas en los sucesivos congresos de la Asociación Latinoamericana de Sociología, evidenciamos la existencia de un conjunto de obstáculos epistemológicos en los estudios urbanos, que no sólo dificultaban comprender el fenómeno de la vida de los habitantes de las ciudades de América Latina, sino también reproducían - fortaleciendo -, un pensamiento sin perspectiva alguna para superar la llamada "crisis urbana", a través de una gama de posibles intervenciones que no hacían sino profundizar las condiciones adversas de los pobladores.

El principal origen de esos obstáculos epistemológicos se encontraba en las formas que había adquirido la producción de verdad en el ámbito de la academia y la denominada "investigación científica" en las comunidades y corporaciones del conocimiento en América Latina. En relación con la dinámica de la acción de los diversos grupos sociales, las respuestas estructuradas en el plano académico no nos ofrecían un marco explicativo, particularmente 
en los aspectos relacionales entre las diferentes personificaciones.

La causa, hipotetizábamos ya en aquel entonces, residía en la raíz de las reflexiones, en la casi totalidad de los casos, cimentada en las políticas neoliberales - en principio emanadas desde los organismos financieros internacionales $y$, a continuación, desde los investigadores locales alineados en la ciencia normal. Es decir, lo que no estaba presente en esas reflexiones (aún hoy de uso hegemónico), en los niveles de las acciones sociales, era la dinámica de las fracciones sociales directamente involucradas en la acción, en términos de alianzas y enfrentamientos.

En el desarrollo de los diversos procesos de asentamiento, los sujetos actuantes - en los distintos casos - constituyen conjuntos de relaciones sociales estructurados bajo forma de instituciones o personificaciones, que sintetizan, en su corporeidad, determinados conjuntos de relaciones, que, en general, operan bajo una lógica determinada por una sumatoria (variable en sus magnitudes y contradictorias, por lo tanto en conflicto permanente) de intereses en los planos económicos, políticos o corporativos.

Empero, nuestras reflexiones críticas conceptuales, sostenidas con avances empíricos que refutaban rigurosamente aquel "sentido común", eran un susurro que se mantuvo históricamente acallado.

En el contexto de polémicas recientes, este trabajo vuelve sobre la revalorización de las sugerencias de Marx y Engels, Piaget y Lefebvre, entre otros autores, sosteniendo la fertilidad de una mirada que parte de la génesis e historicidad de los procesos, contra las visiones hegemónicas que naturalizan el orden social y fetichizan los objetos y las políticas urbanas.

Finalmente, atentos a lo nuevo, pensamos que nuestro desafío de intelectuales está en construir los instrumentos que en lugar de desarmarnos intelectualmente en teorías de lo imposible o entretenernos en los juegos de pensamientos ajenos, nos armemos teórica y moralmente, en nuestros ámbitos, y podamos armar a las multitudes en actitudes de autonomía y cooperación.

\section{Ana Núñez}

Universidad Nacional de Mar del Plata, Facultad de Arquitectura, Urbanismo y Diseño, Instituto de Investigaciones en Desarrollo Urbano, Tecnología y Vivienda. Mar del Plata, Província de Buenos Aires, República Argentina.

aenunez@mdp.edu.ar

\section{Jorge Roze}

Universidad Nacional del Nordeste, Facultad de Humanidades. Chaco, Corrientes, República Argentina.

jorgeroze45@hotmail.com 


\section{Notas}

(*) Este artículo es la ponencia homónima, presentada en el I Seminario Internacional La ciudad neoliberal en América latina: desafíos teóricos y políticos. Eje (IV) Los modelos de política urbana y el pensamiento neoliberal. Red Latinoamericana de Investigadores sobre Teoría Urbana, Río de Janeiro, 5-8 de noviembre 2013.

(1) Esta misma matriz teórico-metodológica es el andamiaje de nuestros estudios actuales sobre los programas de construcción de viviendas sociales, en distintas ciudades de Argentina. Ver Núñez (2010).

(2) Siguiendo a Zemelman (1987, p. 66), "La idea de apertura se corresponde con el planteamiento de la realidad como proceso y exige que el objeto, a partir y a través del cual se explica algo, se considere siempre abierto a la constante transformación de sus referentes empíricos. La idea de movimiento en que descansa la noción de apertura, se relaciona con el "cómo es" de lo real y con el "cómo es posible de darse" de lo real..." (sub. nuestro).

(3) Cae fuera de los objetivos de esta Introducción, analizar los distintos enfoques que, tanto desde la perspectiva "estadocéntrica" como desde la "sociocéntrica", han contribuido a analizar la relación Estado-sociedad en la definición de políticas públicas. Ver, para ello, un excelente estado de la cuestión en Viguera (1998) y Marques (1997).

(4) Porque, además, siguiendo a Espinosa-Saldaña (1997, pp. 202-207), dentro de las ciencias jurídicas, dos de los puntos más complejos son: a) determinar cuándo estamos o no frente a un derecho fundamental; y b) la definición de cuáles derechos, en concreto, pueden ser considerados como sociales. El difícil acuerdo conduce al regateo de su exigibilidad, tendiendo a negar a algunos derechos de tipo social su carácter de derecho fundamental, aun cuando los organismos internacionales los reconozcan formalmente.

(5) Si bien el Castells de La cuestión urbana alcanza formulaciones de un cierto determinismo al subestimar, en principio, el peso de las contradicciones sociales, su aporte fue fundamental, al menos, al señalar que en los países periféricos el proceso de acumulación y el papel desempeñado en él por el Estado, no repiten el esquema de los países centrales. Ver este tema en Cignoli (1985).

(6) Como bien señala Marques (1997), aun introduciendo el conflicto en la explicación de las políticas urbanas, el Estado aparecía como estructuralmente capturado y el proceso político resultaba en la victoria del capital en general. Para un análisis de las perspectivas analíticas que desde el marco histórico-estructural y desde la economía explicaban la intervención del Estado, ver Marques (1997).

(7) Para este segundo Castells $(1988$, p. 79; 1986) “...sólo las luchas urbanas que producen efectos de transformación en la estructura urbana son movimientos sociales urbanos". Este autor procura caracterizar la contradicción urbana como específica a los problemas de la ciudad, diferenciándola de otros motivos para la movilización social que ocurren en la ciudad (movimientos urbanos). En este sentido, para Pereira (1986) y Cignoli (1997), la limitación de la contradicción en Castells, es que confronta en la esfera del consumo y sólo indirectamente en la de la producción. 
(8) Ver Burki, Perry y Dillinger (1999); y Freire y Stren (2001), ambas publicaciones del Banco Mundial. La nueva estrategia del desarrollo urbano del Banco Mundial difundía que la sustentabilidad de las ciudades debía abarcar cuatro aspectos: ser "habitables" (asegurar una vida decente e igualdad de oportunidades a todos los residentes); ser productivas y "competitivas"; estar bien gobernadas y ser "financiables" (en: Freire, 2001, p. xxii).

(9) A modo de ejemplo, pueden citarse a Dourojeanni (1994); Herzer et al. (1994); Borja y Castells (1997) y la publicación de Antonio Azuela y Emilio Duhau (1993) sobre Gestión urbana y cambio institucional, donde explicitan "la necesidad de dar un giro a los análisis sobre "políticas urbanas", aunque "sin descartar la interpretación general del papel del Estado" (p. 12). El debate que concentra dicha publicación creemos que constituye un avance respecto a los que se encuadran en la perspectiva articuladora de las funciones del municipio (Cfr. Herzer et al., 1994).

(10) Independientemente de su imprecisión, "medios de consumo colectivos" es la expresión que más se ha impuesto y la que se utiliza como referencia, entendiendo por éstos una serie de valores de uso que por alguna de sus características son difíciles de suministrar por el capital individual y, sin embargo, son indispensables para la acumulación del capital en general. Así, su naturaleza pública es el resultado de procesos sociales concretos, históricamente determinados. Ver Coing (1988, p. 88) y Jaramillo (1988, 1986, pp. 19 y ss.)

(11) Categoría censal que en Argentina refiere a "pequeña y mediana industria", en la que se incorporan los emprendedores individuales y familiares, cuentapropistas, y todos aquellos que no disputan las tasas de ganancias como burguesías consolidadas en empresas.

(12) Respecto de las identidades, resulta particularmente pertinente retomar el sentido que le dan, por un lado, Rebón (2007, p. 21), como "concepto que enfatiza el carácter social de una personificación, el haz de relaciones que expresa y su relación en términos de funcionalidad con el orden social en el que está inmerso. La conformación de las identidades sociales no puede comprenderse sin tener en cuenta el desarrollo de la confrontación entre las mismas".

(13) En palabras de Roze (1993), "No se trata de la materialidad de ese elemento de mediación ni de su volumen o costo sino que (la vivienda) enlaza relaciones que hacen a la casi totalidad de aspectos de las condiciones de producción y reproducción de la fuerza de trabajo en nuestras formaciones sociales".

(14) Dice Paul Bromberg (2011), avanzando sobre la definición de Weber (1992, pp. 1056-1057), que "Una "sociedad" decide conformarse como Estado mediante un proceso en el que un grupo, o una alianza de grupos dentro de ella (la sociedad), logran consolidar su capacidad exclusiva para emplear la violencia física con el fin de hacer valer sus órdenes... Este acuerdo implica, entre otras cosas, que ese grupo o grupos deciden y hacen valer con éxito una frontera territorial (...) El Estado, así pensado, abarca entonces (1) territorio, (2) habitantes y (3) un aparato. Este último concreta, en forma de entidades compuestas por personas con atribuciones establecidas, las reglas definidas por el grupo o por la alianza de grupos para la toma de decisiones que deben ser acatadas por los integrantes de la sociedad, bajo la amenaza del ejercicio de la violencia física sobre quienes no las acatan." (Material de clase del Curso de Posgrado Gobierno de la ciudad y políticas públicas, en el marco de la Especialización en Políticas y Mercados de Suelo en América Latina, Universidad Nacional de Colombia). Sin embargo, para Lourau (1980, p. 29) al servirse de todos los recursos ideológicos para imponer una forma equivalente a todas las relaciones sociales sometidas a su poder, el Estado dispone de un instrumento de coacción que torna inútil la distinción entre Estado y aparatos ideológicos del Estado. 
(15) Entendemos por estatalidad profunda (territorialidad burguesa), las estrategias de reproducción adaptativas; trayectorias, vínculos y relaciones sociales en el entramado de instituciones políticas; entre el secreto y la lucha por abrirse camino (Marx, 1968); y por estatalidad extensa a la permeabilidad hacia y con el exterior (burocracia, empresas, vecinos), a la construcción y reproducción de estrategias y categorías que reproducen el orden dominante en las instituciones sociales. Se trata de ver cómo ambas se vertebren y se mantienen en una vaporosa indefinición, en cuanto a límites y contenidos, y así se instala en el imaginario (Lourau, 1980). Ver Núñez (2007).

(16) El blindaje, el cierre social, refiere a que determinados grupos sociales se apropian y reservan para sí mismos - o para otros allegados a ellos - ciertas posiciones sociales. En: Ansaldi (1997).

(17) Una fuerza social es una alianza de clases, entre fracciones de clases, que tienen distintos grados de unidad de clase (Roze, 1993, 2003).

(18) Esta misma matriz teórico-metodológica es el andamiaje de nuestros estudios actuales sobre los programas de construcción de viviendas sociales, en distintas ciudades de Argentina. Ver Núñez (2010). Asimismo, para un análisis más exhaustivo de estas políticas urbanas en Argentina, remitimos al lector a nuestra bibliografía citada, de manera de no extender este texto.

(19) El límite urbano de provisión de agua en la ciudad fue fijado por Ordenanza del 3 de agosto de 1937, Exp. 158-0-1937. Asimismo, la Ley 12140/35 preveía el abastecimiento de provisión de agua mediante grifos públicos. Es decir, la carencia y la precariedad se legislan, se construyen y se extienden estatalmente.

(20) El Decreto 33425/44 fundía Obras Sanitarias de la Nación - OSN y la Dirección General de Irrigación en la Administración Nacional del Agua. Establecía, en uno de sus artículos, la obligatoriedad de pagar a todo propietario cuyo inmueble estuviera localizado dentro del cerco, estuviera o no abastecido de agua. Es decir, se crea el contribuyente no usuario.

(21) Se crea por Ley 13577/49, que será la nueva Carta orgánica de OSN, confiriéndole autarquía.

(22) La transferencia de OSN era un proyecto dentro del programa de modernización del aparato estatal de la burguesía desarrollista y de la necesidad de divisas para implementar su política. La alianza con la burguesía extranacional, a través de la Alianza para el Progreso, retrotrajo a la población a fines del siglo XIX, reinsertando el miedo a la muerte, pero sembrando el camino al agua con condiciones de propiedad, heteronomía y capacidad de pago. Para el Banco Mundial, la amenaza, la causa de la elevada mortalidad era la intensa presión del crecimiento demográfico. $\mathrm{O}$, en otros términos, la urbanización de la pobreza.

(23) Servicio Nacional de Agua Potable, creado por Decreto n. 9762, dentro del Plan Decenal de Salud Pública de la Alianza para el Progreso. En el ámbito local, se profundizó la provisión de grifos públicos y se implementaron préstamos para compra de bombas manuales.

(24) No debe olvidarse que, a fines de la década de 1990, los organismos internacionales de crédito promueven la reformulación del sistema político y la superación de la crisis de representación alentando la disolución de todo lazo entre representantes y representados, asumiendo que los sectores populares son incapaces de tomar decisiones y de participar con autonomía en la definición de su propio destino. El Programa de financiamiento a municipios, con aportes del Banco Mundial - BM y el Banco Internacional de Desarrollo - BID de U\$S420 millones en 1999 a la ciudad de Mar del Plata, apunta en esta dirección.

(25) Estas identidades sociales surgieron de entrevistas abiertas en los barrios, que no transcribimos por razones de espacio. Ver Núñez (2007). 
(26) Siguiendo a Piaget y García (1985, p. 81), una pseudo necesidad es un fenómeno corriente que se ubica en los primeros niveles de la génesis del conocimiento y que expresa la dificultad de imaginar otros posibles diferentes $y$, como tal, constituyen una fase de indiferenciación entre lo real, lo posible y lo necesario (Roze, 2003).

(27) Un cierto número de conclusiones obtenidas a partir del estudio de campo produjeron un efecto intranquilizador sobre los responsables de la ejecución de programas federales de control de inundaciones, provocando la iniciación de nuevas investigaciones para indagar más a fondo las cuestiones que no habían quedado resueltas. Como resultado de estos nuevos trabajos, se vino a descubrir que mientras los gastos hechos para el control de inundación se habían multiplicado considerablemente, el nivel de daños producidos se había elevado también, por lo que resultaba que, con la ejecución de las obras proyectadas para el control de las avenidas, no se había conseguido alcanzar el objetivo nacional de reducir el tributo que suponían las pérdidas y daños sufridos por el país por tal concepto (White, 1973, p. 291).

(28) Cuando en el III Seminario sobre el Impacto de las Inundaciones en Resistencia, se plantea una exposición de este tipo de tecnologías, la iniciativa no prosperó, al igual que toda otra que no supusiera idefensas definitivas ya! No queremos con este señalamiento que se pueda inducir que nuestro pensamiento se inscribe en "lo pequeño es hermoso" - tan de moda en décadas pasadas - o en la línea, - fuertemente impulsada del Banco Mundial - de las tecnologías adecuadas o apropiadas. Simplemente, dejamos constancia de la existencia de respuestas locales cuya diseminación debió haber constituido una de las tantas alternativas a la emergencia hídrica y fue también transformada en un inobservable.

\section{Referencias}

ANSALDI, W. (1997). Fragmentados, excluidos, famélicos y, por si eso fuera poco, violentos y corruptos. Revista Paraguaya de Sociología, año 34, n. 98, pp. 7-36. Asunción, Centro Paraguayo de Estudios Sociológicos. Disponível em: http://catedras.fsoc.uba.ar/udishal/art/fragmentados.pdf

AZPIAZU, D. e FORSINITO, K. (2001). La privatización del sistema de agua y saneamiento en el Área Metropolitana de Buenos Aires. Discontinuidad regulatoria, incumplimientos empresarios, ganancias extraordinarias e inequidades distributivas. Mimeo.

AZUELA, A. e DUHAU, E. (coords.) (1993). Gestión urbana y cambio institucional. México, IIS/UAM/IFAL. BACHELARD, G. (1987). La formación del espíritu científico. México, Siglo XXI.

BALVÉ, B. e BALVÉ, B. (2005). El '69. Huelga política de masas. Rosariazo-Cordobazo-Rosariazo. Buenos Aires, RyR/CICSO/Ediciones ryr.

BIRD, R. (2001). "Cargos a los usuarios en las finanzas del gobierno local”. In: FREIRE, M. e STREN, R. (eds.). Los retos del gobierno urbano. Instituto del Banco Mundial \# 21642. Colômbia, Banco Mundial/Alfaomega, pp. 164-176. 
BORJA, J. e CASTELLS, M. (1997). Local y global. La gestión de las ciudades en la era de la información. Madri, Taurus.

BURKI, S.; PERRY, G. e DILLINGER, W. (1999). Más allá del centro. La descentralización del Estado. Estudios del Banco Mundial sobre América Latina y el Caribe. Washington, Banco Mundial.

CAPUTO, M. G.; HARDOY, J. E.; HERZER, H. M. e VARGAS, R. (1985). La inundación en el Gran Resistencia (Provincia del Chaco, Argentina) 1982-1983.Desastres naturales y Sociedad en América Latina. Buenos Aires, CLACSO. Colección Estudios Políticos y Sociales.

CAPUTO, M. G. e HERZER, H. M. (1987). Reflexiones sobre el manejo de las inundaciones y su incorporación a las políticas de desarrollo regional. Desarrollo Económico, v. 27, n. 106. Buenos Aires, Ides.

CASTELLS, M. (1978). La cuestión urbana. México, Siglo XXI.

CASTRO, E. (1999). El retorno del ciudadano: los inestables territorios de la ciudadanía en América Latina. Perfiles latinoamericanos, \# 14. México, FLACSO, pp. 39-62.

CIGNOLI, A. (1985). Estado e força de trabalho. Introduçao à política social no Brasil. São Paulo, Brasiliense.

COING, H. (1988). Serviços urbanos: velho ou novo tema? Espaço \& Debates, n. 23. São Paulo.

DOUROJEANNI, A. (1994). La gestión del agua y las cuencas en América Latina. Revista de la CEPAL, n. 53, pp. 111-127. Santiago de Chile.

ELÍAS, N. (1982). Sociología fundamental. Barcelona, Gedisa. Serie Mediaciones.

ESPINOSA-SALDAÑA, E. (1997). “Apuntes sobre las dificultades existentes para la protección de los derechos sociales en el modelo de jurisdicción constitucional español”. In: BIDART CAMPOS, G. (comp.). Economía, constitución y derechos sociales. Buenos Aires, Ediar.

FREIRE, M. (2001). "Introducción”. In: FREIRE, M. e STREN, R. (eds.). Los retos del gobierno urbano. Instituto del Banco Mundial \#21642. Colômbia, Banco Mundial/Alfaomega.

FREIRE, M. e STREN, R. (eds.) (2001). Los retos del gobierno urbano. Instituto del Banco Mundial \#21642. Colômbia, Banco Mundial/Alfaomega.

GARCÍA, R.; INHELDER, B. e VOLNÉCHE, J. (comps.) (1977). Epistemología genética y equilibración (Homenaje a Jean Piaget). Buenos Aires, Huemul.

HERZER, H.; PÍREZ, P. e RODRÍGUEZ, C. (1994). Modelo teórico conceptual para la gestión urbana en ciudades intermedias de América Latina. Santiago de Chile, Cepal, LC/R 1407.

HERZER, H. M. (1990). Los desastres no son tan naturales como parecen. Medio Ambiente y Urbanización, año 8, n. 30. Buenos Aires, IEED.

HOLLOWAY, J. (1994). Marxismo, Estado y capital. La crisis como expresión del poder del trabajo. Fichas temáticas de Cuadernos del Sur. Buenos Aires, Tierra del Fuego.

JARAMILLO, S. (1986). Crise dos meios de consumo coletivo urbano e capitalismo periférico. Espaço \& Debates, ano VI, n. 18, pp. 19-39. São Paulo, Neru.

JARAMILLO GONZÁLEZ, S. (1988). “Crisis de los medios de consumo colectivo urbano y capitalismo periférico". In: CUERVO, L. e JARAMILLO, S. et al. Economía política de los servicios públicos. Una visión alternativa. Bogotá, Cinep. 
LEFEBVRE, H. (1969). El derecho a la ciudad. Barcelona, Península.

(1971). El materialismo dialéctico. Buenos Aires, La Pléyade.

(1972). La revolución urbana. Madri, Alianza.

(1976). Espacio y política. El derecho a la ciudad II. Barcelona, Península.

(2011). La noción de totalidad en las ciencias sociales. Telos, v. 13, n. 1, pp. 105-124. Maracaibo, Universidad Rafael Belloso Chacín.

LIPIETZ, A. (1979). El capital y su espacio. México, Siglo XXI.

LOFTUS, A. e McDONALD, D. (2004). Sueños líquidos: una ecología política de la privatización del servicio de agua en Buenos Aires. Realidad Económica, n. 183. Buenos Aires, lade.

LOJKINE, J. (1979). El marxismo, el Estado y la cuestión urbana. México, Siglo XXI.

LOURAU, R. (1980). El Estado y el inconsciente. Ensayo de sociología política. Barcelona, Kairos.

MARÍN, J. C. (1996). Conversaciones sobre el poder (una experiencia colectiva). Buenos Aires, Instituto Gino Germani, Oficina de Publicaciones CBC, UBA.

MARQUES, E. (1997). Notas críticas à literatura sobre Estado, políticas estatais e atores políticos. Boletim Bibliográfico de Ciências Sociais, n. 43. Rio de Janeiro.

MARX, C. (1965). El Capital. Buenos Aires, Cartago.

(1968). Crítica de la filosofía del Estado de Hegel. México, Grijalbo.

(1998). El Dieciocho Brumario de Luis Bonaparte. Buenos Aires, Libertador.

MARX, C. e ENGELS, F. (1968). La ideología alemana. Montevideo, Pueblos Unidos.

NEIF, J.; PATIÑO, C. A. e ORFEO, O. (1987). Pautas para el manejo de plataformas y taludes en áreas inundables. Centro de Ecología Aplicada del Litoral (Cecoal-Conicet). Serie Técnica n. 2.

NÚÑEZ, A. (1994). Apropiación de la tierra y organización territorial en una ciudad media argentina. EI caso de Mar del Plata. Revista Interamericana de Planificación, v. I. XXVII, n. 107-108. Equador, SIAP.

(2000)[2012]. Morfología social. Mar del Plata, 1874-1990. Tandil, Grafikart.

(2007). Política urbana y proceso de estatalidad. Confluências. Revista interdisciplinar de sociologia e direito, n. 9. Rio de Janeiro, Universidade Federal Fluminense.

(2010). "Tras el fetichismo de la vivienda digna". In: ORTECHO, E.; PEYLOUBET, P. e DE SALVO, L. (comps.). Ciencia y Tecnología para el Hábitat Popular. Fortalecimiento del espacio disciplinar en los Sistemas Científico Tecnológicos (seleccionado por referato internacional). Buenos Aires, Nobuko.

(2011). Formas socioterritoriales de apropiación del habitar y derecho al espacio diferencial. Revista Territorios, n. 24, pp. 165-192. Bogotá, Universidad del Rosario.

(2012) [2006]. Lo que el agua (no) se llevó...Política urbana: poder, violencia e identidades sociales. Buenos Aires, El Colectivo.

NÚÑEZ, A. e CIUFFOLINI, M. A. (eds. e comps.) (2011). Política y territorialidad en tres ciudades argentinas. Buenos Aires, El Colectivo. 
NÚÑEZ, A. e ROZE, J. (2011). Reflexiones sobre falacias conceptuales y acciones concomitantes en políticas urbanas y sociales en Argentina. Revista Theomai. Estudios sobre sociedad y desarrollo, n. 23, pp. 193-204. Buenos Aires, Universidad Nacional de Quilmes.

OSZLAK, O. (1997). Estado y sociedad: ¿nuevas reglas de juego? Reforma y Democracia, Revista del CLAD. Caracas, CLAD.

PEREIRA, X. (1986). Valorização imobiliária, movimentos sociais e espoliação. Sinopses, \#9. São Paulo, Fauusp.

PIAGET, J. e GARCIA, R. (1984). Psicogénesis e historia de la ciencia. México, Siglo XXI.

PÍREZ, P. (1995). Actores sociales y gestión de la ciudad. Ciudades, n. 28, pp. 8-14. Puebla, RNIU.

(2013). Perspectivas latinoamericanas para el estudio de los servicios urbanos. Cuaderno urbano. Espacio, cultura, sociedad, n. 14. Resistencia, Nobuko/UNNE.

POPOLIZIO, E. (en col. con Oscar Bonfanti) (1985). “Bases y criterios para la concepción de obras de infraestructura vinculada con las inundaciones". In: Inundaciones y Sociedad en el Gran Resistencia, Chaco, 1982-83. Buenos Aires, Ediciones Boletín de medio ambiente y urbanización. CLACSO.

PRADILLA COBOS, E. (2009). La mundialización, la globalización imperialista y las ciudades latinoamericanas. Bitácora, n. 15, pp. 13-36. Bogotá, Universidad Nacional de Colombia.

(2010). Teorías y políticas urbanas: ¿libre mercado mundial o construcción regional? Revista Brasileira de Estudos Urbanos e Regionais, v. 12, n. 2. São Paulo.

REBÓN, J. (2007). La empresa de la autonomía. Trabajadores recuperando la producción. Buenos Aires, Colectivo/P.I.CA.SO.

ROSENZVAIG, E. (2004). Pabellón de rurales. Herramienta, Revista de debate y crítica marxista, n. 27. Buenos Aires, Herramienta.

ROZE, J. (1993). Desastres recurrentes y conflictos sociales. Tomas de viviendas en el marco de las inundaciones de 1983 1986. Cuaderno 1, Cátedra de Sociología Urbana. Resistencia, Facultad de Arquitectura y Urbanismo, Universidad Nacional del Nordeste.

(1995). Espacio y poder. Una mirada material. Cuaderno Urbano 2. Cátedra de Sociología Urbana. Resistencia, FAU/UNNE.

(2001). Las ciudades y la acción sobre las ciudades. AREA - Agenda de reflexión en arquitectura, diseño y urbanismo, n. 9. Secretaría de Investigación en Ciencia y Técnica, Facultad de Arquitectura, Diseño y Urbanismo, Universidad de Buenos Aires.

(2003). Inundaciones recurrentes: ríos que crecen, identidades que emergen. Ediciones Al Margen. Colección Entasis. La Plata, Fundación IDEAS Ediciones.

ROZE, J. et al. (1999). Trabajo, moral y disciplina en los chicos de la calle. Buenos Aires, Espacio.

SIR WILLIAM HALCROW e PARTNERS LTD. (1994). Estudio de regulacion del valle aluvional de los ríos Paraná, Paraguay y Uruguay para el control de las inundaciones. Informe final. Buenos Aires, Sub Unidad de Coordinación para la Emergencia/Ministerio del Interior.

STREN, R. (2001). "Participación del sector privado en el suministro de los servicios públicos" e "Introducción" (a varios capítulos). In: FREIRE, M. e STREN, R. (eds). Los retos del gobierno urbano. Instituto del Banco Mundial \#21642. Colômbia, Banco Mundial/Alfaomega. 
TOPALOV, C. (1979). La urbanización capitalista. Algunos elementos para su análisis. México, Edicol.

VIGUERA, A. (1998). Estado, empresarios y reformas económicas. En busca de una perspectiva analítica integradora. Perfiles latinoamericanos, año 7, n. 12, pp. 9-51. México, FLACSO.

WHITE, G. F. (1973). "La investigación de los riesgos naturales". In: CHORLEY, R. J. Nuevas tendencias en geografía. Madri, Colección Nuevo Urbanismo. Instituto de Estudios de la Administración Local.

YUJNOVSKY, O. (1984). Claves políticas del problema habitacional argentino. Buenos Aires, GEL.

ZEMELMAN, H. (1987). La totalidad como perspectiva de descubrimiento. Revista Mexicana de Sociología, v. 49, n. 1. México, Instituto de Investigaciones Sociales/UNAM.

Texto recebido em 4/nov/2013

Texto aprovado em 15/dez/2013 